\title{
Air Pollution and Dispensed Medications for Asthma, and Possible Effect Modifiers Related to Mental Health and Socio-Economy: A Longitudinal Cohort Study of Swedish Children and Adolescents
}

\author{
Anna Oudin *, Lennart Bråbäck, Daniel Oudin Åström and Bertil Forsberg \\ Occupational and Environmental Medicine, Umeå University, 90187 Umeå, Sweden; \\ Lennart.Braback@umu.se (L.B.); Daniel.oudin_astrom@med.lu.se (D.O.Å.); bertil.forsberg@umu.se (B.F.) \\ * Correspondence: anna.oudin@umu.se
}

Received: 22 September 2017; Accepted: 11 November 2017; Published: 16 November 2017

\begin{abstract}
It has been suggested that children that are exposed to a stressful environment at home have an increased susceptibility for air pollution-related asthma. The aim here was to investigate the association between air pollution exposure and asthma, and effect modification by mental health and by socio-economic status (as markers of a stressful environment). All individuals under 18 years of age in four Swedish counties during 2007 to 2010 (1.2 million people) were included. The outcome was defined as dispensing at least two asthma medications during follow up. We linked data on $\mathrm{NO}_{2}$ from an empirical land use regression to data from national registers on outcome and potential confounders. Data was analyzed with logistic regression. There was an odds ratio (OR) of 1.02 (95\% Confidence Interval (CI: 1.01-1.03) for asthma associated with a $10 \mu \mathrm{g} \cdot \mathrm{m}^{-3}$ increase in $\mathrm{NO}_{2}$. The association only seemed to be present in areas where $\mathrm{NO}_{2}$ was higher than $15 \mu \mathrm{g} \cdot \mathrm{m}^{-3}$ with an OR of 1.09 (95\% CI: 1.07-1.12), and the association seemed stronger in children with parents with a high education, $\mathrm{OR}=1.05$ (95\% CI: 1.02-1.09) and OR $=1.04$ (95\% CI: $1.01-1.07$ ) in children to mothers and father with a high education, respectively. The association did not seem to depend on medication history of psychiatric disorders. There was weak evidence for the association between air pollution and asthma to be stronger in neighborhoods with higher education levels. In conclusion, air pollution was associated with dispensed asthma medications, especially in areas with comparatively higher levels of air pollution, and in children to parents with high education. We did not observe support for our hypothesis that stressors linked to socio-economy or mental health problems would increase susceptibility to the effects of air pollution on the development of asthma.
\end{abstract}

Keywords: asthma; childhood asthma; air pollution; stress; socio-economy; mental health

\section{Introduction}

Asthma is one of the most common chronic diseases in children. Despite decades of intense research, the etiology and pathogenesis are still partly unknown, although environmental exposures in infancy [1] and stress are of importance [1-7]. Negative life events can cause asthma attacks in children, especially if they are exposed to chronic stress [8]. Furthermore, there is a strong association between respiratory symptoms and psychological status [9], and parents' mental health is associated with childhood asthma in the offspring [10]. The causal relationship between asthma and mental health/stress seem to point in both directions because asthma is strongly related to perceived life quality but can also yield anxiety and fatigue. Childhood asthma has received a lot of attention as a cause for mental health problems as it, for example, is a risk factor for neuropsychiatric disease [11].

Long-term exposure to air pollution seem to be a risk factor for asthma [2,12], reduced lung function [13], and sensitization [14], although some large studies have been negative [15]. Interestingly, 
it has been suggested that children that are exposed to a stressful environment at home have an increased susceptibility for air pollution-related asthma [16,17].

Physical health and mental health are thus intertwined, but air pollution can also have a direct negative effect on the brain, for example cognitive development $[18,19]$, cognitive decline and dementia [20-22]. Experimental studies show that an association between air pollution exposure and mental health is plausible [23]. Anxiety disorders and schizophrenia are more common in urban areas [24,25], which can be attributed to urban social environment, but possibly thus also to environmental factors. We recently showed that air pollution was associated with medications for psychiatric disorders in Swedish children and adolescents [26], and there is support for air pollution exposure during fetal life to increase risk of autism $[27,28]$, and for air pollution to be linked to behavioral problems in children $[29,30]$.

In summary, the relationship between asthma, mental health, stress, socio-economy and air pollution is likely highly complex (Figure 1). Our hypothesis is that mental health and socio-economy modify the association between air pollution and pediatric asthma, with the theory that stressors linked to socio-economy or mental health problems directly lead to deteriorated health, that susceptibility for air pollution is increased through alterations in the immune system or other biological systems [31], that city dwellers react differently to stress than persons residing in rural areas [32], or that air pollution cause affective responses or impair cognition.

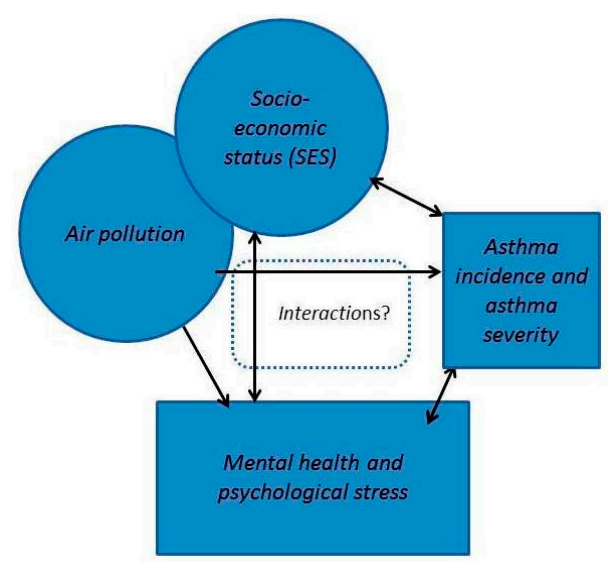

Figure 1. Possible causal pathways between exposure to air pollution, mental health, socioeconomic status and asthma.

The aim of the present study was to investigate the association between air pollution exposure and dispensed medications for asthma, and if that association was modified by mental health or by socio-economic status, in a large cohort of Swedish children and adolescents, to somewhat disentangle this complex relationship.

\section{Materials and Methods}

\subsection{Study Area and Cohort}

The study area and cohort have been described in detail elsewhere [26], but briefly, we used a prospective cohort design where all individuals under 18 years of age who at any time during 1 January 2007-31 December 2010 had a registered residential address in any of the four Swedish counties of Stockholm, Västra Götaland, Skåne and Västerbotten (Figure 2). 

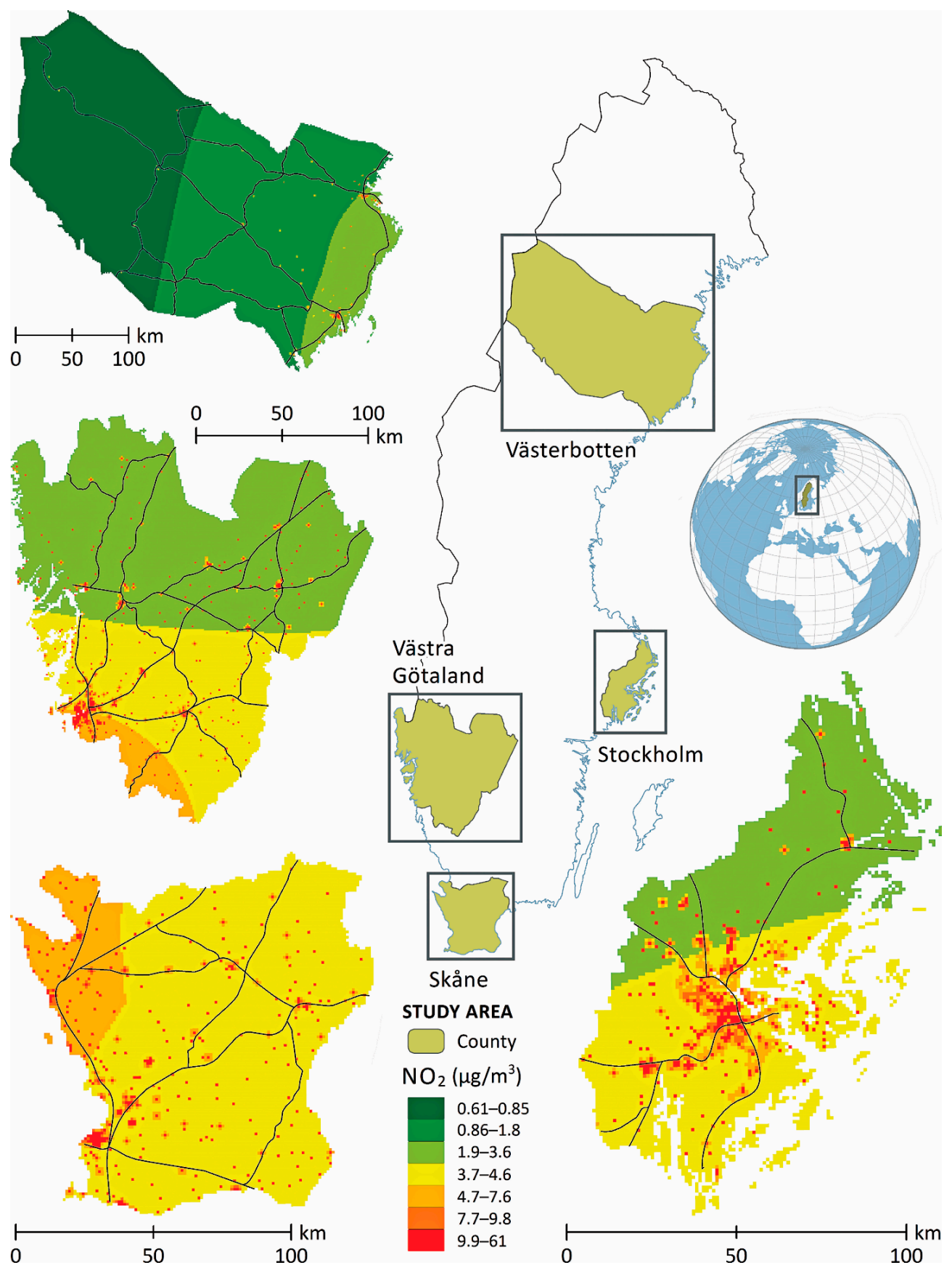

Figure 2. Concentrations of $\mathrm{NO}_{2}$ modelled by the Swedish Research Institute in the four counties of the study area.

The four counties encompass more than half the Swedish population and are heterogeneous in terms of geographical location, population size and population density but also with respect to migration, socioeconomic characteristics, and urbanization and air pollution concentrations.

\subsection{National Register Data}

We used data from the Umeå SIMSAM lab [33]. Data in the lab comes from national registers (which covers the entire Swedish population) and local registers, which were combined via the personal identification number for the use of research. For the present study, we used data from the Swedish National Board of Health and Welfare on a group of dispensed medication related to asthma, both long acting and rescue medications, namely medications starting with the following 
Swedish ATC codes: R03AC (selective beta-2 stimulating medications), R03AK (adrenergic and other medications for obstructive airway disease), R03BA (glucocorticoids), R03BC (anti allergic medications, except corticosteroids), R03CC (selective beta-2-stimulating medications) and R03DC (leukotriene receptor antagonists). We defined the outcome as dispensing at least two dispensed medications with any of these codes. By defining the outcome as at least two dispensed asthma medications during follow-up, our aim was to capture patients more likely to have asthma than patients who only dispensed asthma medications once. Many children with respiratory symptoms, especially very young children, are prescribed asthma medications to evaluate if their symptoms decrease by medication. We thus wanted to avoid to classify children with unspecified respiratory symptoms as asthmatics. We also used data on dispensed medications for psychiatric disorders, namely medications with an ATC-code starting with N05 and N06, hereafter referred to as N05 and N06. N05 consists of neuroleptics (antipsychotic medications), ataractics and sleeping pills (a broad group of sedative medications including hydroxyzine and melatonin-based medications). N06 consist mainly of anti-depressants and ADHD medications when prescribed to children. We defined two variables as dispensed N05 or N06 during baseline (when follow-up started). From the medical birth registry we used information on maternal body mass index in early pregnancy (continuous variable) and maternal smoking during early pregnancy (three categories) Furthermore, from Statistics Sweden we used data on age at the start of follow-up (continuous variable), sex, maternal and paternal education level (four categories) at start follow-up and yearly data on parental unemployment (yes/no). Based on data from Statistics Sweden we defined a group-level (neighborhood) variable on socioeconomic status on Small Areas for Market Statistics (SAMS), namely the proportion of the population in the SAMS area with three or more years of undergraduate studies in the age category 25-65 years. SAMS are supposed to represent homogeneous neighborhoods and there are 6016 SAMS areas in our study area. The quartiles of the variable was $<14 \%, 14 \%<20 \%, 20 \%<32 \%$ and $\geq 32 \%$ with three or more years of undergraduate studies in the age category $25-65$ years.

\subsection{Air Pollution Exposure Assessment}

The Swedish environmental research institute has developed an empirical Land Use Regression model to estimate the urban contribution of $\mathrm{NO}_{2}$ added to the regional background level. The model is based on the ratio of the urban content contribution, the meteorological parameters and the population distribution. It takes into account that the levels are not evenly distributed across a city but related to population density by including the spatial distribution of the urban contribution [34]. The base year of the land use regression model was 2010 and the spatial resolution was $1 \mathrm{~km}^{2}$. The model has previously been showed to have fairly good accordance with a dispersion mode [35].

This model was used together with a model for the regional background levels built on monitoring data to calculate exposure estimates of $\mathrm{NO}_{2}$ the entire Swedish population, for the year when the individual was included in the study (any year between 2005 and 2010). We used this measure as a marker of long-term exposure to air pollution with the underlying assumptions that the concentration at study inclusion was a valid marker for long-term exposure, and that the spatial contrasts in exposure during follow-up were fairly constant. The study was approved by the regional ethics board in Umeå (Dnr 2010-157-31).

\subsection{Statistical Analysis}

The data was analyzed with logistic regression. The results are presented as Odds ratios (ORs) and their $95 \%$ CIs. We studied $\mathrm{NO}_{2}$ as a continuous variables, and present ORs associated with pollutant increases of $10 \mu \mathrm{g} \cdot \mathrm{m}^{-3}$. The initial cohort size was 1,294,290, but we excluded study persons with any dispensed asthma medication during 2005 or 2006 to somewhat capturing incident cases, and the cohort size was reduced to 1,215,754 individuals (Figure 3). It should be noted that we had no records of dispensed medications before 2005, and therefore children denoted incident cases in our study may be not be true new cases, but only new cases since 2005. Individuals with missing data on any of 
the variables included in the main adjusted model (age, sex, parental education, smoking and BMI during early pregnancy) were excluded from the main analysis. The total size of the complete cohort was 745,171 individuals. We used an open cohort approach. Individuals who moved into, or out of, the study areas during follow-up were thus included or excluded in the cohort on December 31 (due to register-technicalities) of the year they moved in or out. Children who were born or died during follow-up were included/excluded at time of birth/death.

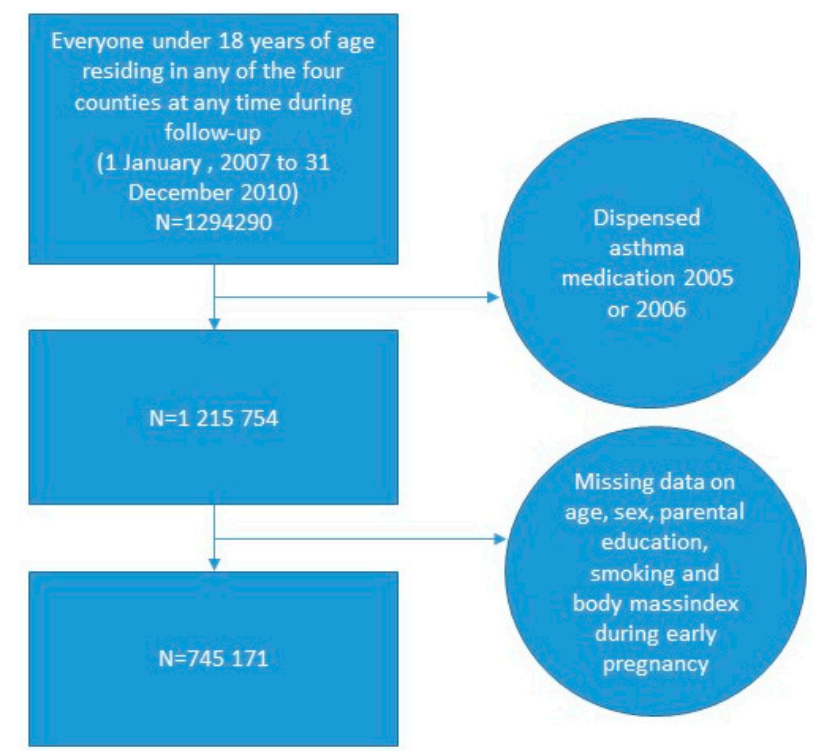

Figure 3. Study flow-chart.

In an additional analysis, we adjusted the models for maternal and paternal income. Further, we stratified our analyses on parental education, previous dispensed N05 or N06, parental unemployment, and area SES. We also ran age-specific analyses for the age at baseline groups $0<5,5<10,10<15$ and $15-18$. We evaluated the presence of heterogeneity in the county-specific results by including a cross-product term in the equation. Otherwise we refrained from calculating $p$-values for effect modification since the size of the cohort would mean that most $p$-values were highly statistically significant and instead assessed effect modification by stratifying analysis and visually inspecting of the association estimates.

\subsection{Sensitivity Analyses}

To check if the associations was present in low-level areas, we ran a threshold analysis where we stratified data on $\mathrm{NO}_{2}$ levels of $15 \mu \mathrm{g} \cdot \mathrm{m}^{3}$. Since asthma medications are prescribe very frequently to small children we excluded children below the age of two in a sensitivity analysis. In another analysis, we delayed start of follow-up one year, to 1 January 2008. We also restricted the analysis to those children and adolescents who resided in the same address for at least two year from start of follow-up. Finally, we investigated if patterns of missingness among our variables was differential with respect to the outcome or level of exposure. We imputed missing observations in the covariates using a Markov Chain Monte Carlo approach and reran the main analyses to investigate whether our estimates changed. We also calculated a pooled estimate from the county-specific estimates. The main analysis was run also with Cox regression, and mixed logistic regression to take into account the multilevel nature of data (county-level). SAS V.9.2 (SAS, Stockhom, Schweden) software was used to create data sets and run the analyses. 


\section{Results}

None of the background factors had a clear univariate association with medications for asthma, except age, with the youngest children as expected being medicated to a higher extent (Table 1). Furthermore, in the univariate analysis there were no marked heterogeneity in $\mathrm{NO}_{2}$ with respect to any of the factors in the study (Table 1).

Table 1. Descriptive data for variables used in the study, stratified by asthma medication and mean levels of $\mathrm{NO}_{2}\left(\mu \mathrm{g} \cdot \mathrm{m}^{-3}\right)$.

\begin{tabular}{|c|c|c|c|c|}
\hline \multirow[b]{2}{*}{ Variables } & \multirow{2}{*}{ Categories } & \multicolumn{2}{|c|}{ Asthma Medication * } & \multirow{2}{*}{$\frac{\text { Mean } \mathrm{NO}_{2}}{\left(\mu \mathrm{g} \cdot \mathrm{m}^{-3}\right)}$} \\
\hline & & $\begin{array}{c}\text { No } \\
\mathbf{N}\end{array}$ & $\begin{array}{c}\text { Yes } \\
\text { N (\%) }\end{array}$ & \\
\hline Boys & & 566,571 & $50,809(8)$ & 10.2 \\
\hline Girls & & 558,711 & $39,663(7)$ & 10.3 \\
\hline \multirow[t]{5}{*}{ Age at baseline } & $<2$ & 303,033 & $56,014(16)$ & 11.4 \\
\hline & $2<5$ & 134,476 & $7466(5)$ & 10.0 \\
\hline & $5<10$ & 229,546 & $11,037(5)$ & 9.7 \\
\hline & $10<15$ & 272,821 & $12,576(4)$ & 9.6 \\
\hline & $15-18$ & 185,406 & $3379(2)$ & 9.8 \\
\hline \multirow[t]{4}{*}{ Smoking early pregnancy } & Missing & 184,807 & $11,722(6)$ & 11.1 \\
\hline & No & 813,138 & $69,803(8)$ & 10.1 \\
\hline & Yes $<10$ cig per day & 83,406 & $6262(7)$ & 9.9 \\
\hline & Yes $\geq 10$ cig per day & 43,931 & $2685(6)$ & 9.8 \\
\hline \multirow[t]{5}{*}{ Mother's education } & Missing & 95,790 & $6723(7)$ & 12.1 \\
\hline & Elementary school & 124,997 & $10,344(8)$ & 11.1 \\
\hline & $\begin{array}{l}\text { Only upper secondary school or } \\
\text { Post-secondary education }<2 \text { years }\end{array}$ & 453,873 & $36,871(8)$ & 9.4 \\
\hline & Post-secondary education $2 \leq 4$ years & 336,162 & $27,173(7)$ & 10.3 \\
\hline & Post-secondary education $\geq 4$ years & 114,550 & $9361(8)$ & 11.1 \\
\hline \multirow[t]{5}{*}{ Father's education } & Missing & 109,437 & $7320(6)$ & 12.0 \\
\hline & Elementary school & 148,970 & $11,815(7)$ & 10.2 \\
\hline & $\begin{array}{l}\text { Only upper secondary school or } \\
\text { Post-secondary education }<2 \text { years }\end{array}$ & 477,250 & $40,059(8)$ & 9.4 \\
\hline & Post-secondary education $2 \leq 4$ years & 258,744 & $21,194(8)$ & 10.7 \\
\hline & Post-secondary education $\geq 4$ years & 130,881 & $10,084(7)$ & 11.2 \\
\hline Group level education ** & quartile $1(<14 \%)$ & 296,380 & $23,106(7)$ & \\
\hline Group level education ** & quartile $2(14-<20 \%)$ & 262,997 & $20,879(7)$ & 8.9 \\
\hline Group level education ** & quartile $3(20 \%<32 \%)$ & 292,250 & $24,230(8)$ & 9.0 \\
\hline Group level education ** & quartile $4(\geq 32 \%)$ & 273,655 & $22,257(8)$ & 14.2 \\
\hline \multirow[t]{2}{*}{ Mother unemployed at baseline } & No & $1,033,154$ & $85,288(7)$ & 10.2 \\
\hline & Yes & 92,128 & $7884(8)$ & 10.5 \\
\hline \multirow[t]{2}{*}{ Father unemployed at baseline } & No & $1,067,643$ & $85,544(7)$ & 10.2 \\
\hline & Yes & 57,639 & $4928(8)$ & 11.5 \\
\hline \multirow[t]{2}{*}{ Analeptika (N06) at baseline } & No & $1,115,524$ & $90,028(7)$ & 10.3 \\
\hline & Yes & 9758 & $444(4)$ & 9.5 \\
\hline \multirow[t]{3}{*}{ Neuroleptika (N05) at baseline } & No & $1,117,444$ & $89,894(7)$ & 10.3 \\
\hline & Yes & 7838 & $578(7)$ & 10.1 \\
\hline & & \multicolumn{2}{|c|}{ Mean } & Spearman rho \\
\hline BMI early pregnancy & & 23.9 & 24.5 & -0.04 \\
\hline Mother's income baseline (SEK) & & 162,600 & 151,200 & -0.03 \\
\hline Father's income baseline (SEK) & & 280,000 & 267,800 & -0.06 \\
\hline $\mathrm{NO}_{2}$ baseline $\left(\mu \mathrm{g} \cdot \mathrm{m}^{-3}\right)$ & & 10.2 & 10.5 & 1 \\
\hline
\end{tabular}

* Defined as dispensing at least two medications with the ATC-codes R03AC, R03AK, R03BA, R03BC, R03CC and R03DC during the study period (2007-2010); ** Proportion in the neighborhood (SAMS area) with three or more years of undergraduate studies in the age category 25-65 years.

However, in young children ( $<2$ years at study entry), there was an association between smoking during early pregnancy and asthma (data not shown). There was an association between medications 
for asthma and $\mathrm{NO}_{2}$ when adjusted for age with an Odds ratio (OR) of 1.05 (95\% Confidence Interval (CI: 1.04-1.06) associated with a $10 \mu \mathrm{g} \cdot \mathrm{m}^{-3}$ increase in $\mathrm{NO}_{2}$ (Table 2).

When adjusted for sex, parental education, smoking during pregnancy and BMI in early pregnancy, the OR was attenuated to 1.02 (95\% CI: 1.01-1.03; Table 2). The estimate that was pooled from the county-specific estimates was 1.06 (95\% CI: 1.02-1.11). The analysis where data was stratified on $\mathrm{NO}_{2}$ above and below $15\left(\mu \mathrm{g} \cdot \mathrm{m}^{-3}\right)$ indicates that the association between $\mathrm{NO}_{2}$ and dispensed asthma medication only seem to be present in areas with higher levels of air pollution, above $15\left(\mu \mathrm{g} \cdot \mathrm{m}^{-3}\right)$ in this study (Table 2$)$. When excluding children under the age of two at study entry, the OR in the adjusted analysis was 1.06 (95\% CI: 1.04-1.09; Table 2), suggesting that the association between air pollution and asthma medications was stronger after early childhood.

Table 2. Odds ratios (ORs) and their 95\% Confidence Intervals (CIs) for asthma medication in association with a $10\left(\mu \mathrm{g} \cdot \mathrm{m}^{-3}\right)$ increase in $\mathrm{NO}_{2}$ for all cohort members, and in sub-groups of the cohort.

\begin{tabular}{|c|c|c|c|c|}
\hline & OR & $95 \%$ CI & & \\
\hline & Age-Adjusted & & Adjusted $^{4}$ & \\
\hline All & 1.05 & $1.04-1.06$ & 1.02 & $1.01-1.03$ \\
\hline \multicolumn{5}{|l|}{ Sub-groups } \\
\hline Mother low education ${ }^{1}$ & 1.01 & $0.98-1.05$ & 0.99 & $(0.95-1.02)$ \\
\hline Mother high education $^{2}$ & 1.04 & $1.01-1.06$ & 1.05 & $1.02-1.09$ \\
\hline Low father education ${ }^{1}$ & 1.03 & $0.997-1.06$ & 0.99 & $0.96-1.027$ \\
\hline Father high education $^{2}$ & 1.03 & $1.00-1.05$ & 1.04 & $1.01-1.07$ \\
\hline Unemployment mother baseline & 1.03 & $1.00-1.07$ & 1.00 & $0.97-1.04$ \\
\hline Unemployment father baseline & 1.06 & $1.02-1.10$ & 1.02 & $0.97-1.06$ \\
\hline \multicolumn{5}{|l|}{ Age baseline } \\
\hline$<2$ & 1.06 & $1.04-1.07$ & 1.02 & $1.01-1.04$ \\
\hline $2 \leq 5$ & 1.05 & $1.01-1.08$ & 1.03 & $0.99-1.08$ \\
\hline $5 \leq 10$ & 1.12 & $1.08-1.15$ & 1.07 & $1.03-1.11$ \\
\hline $10 \leq 15$ & 1.14 & $1.11-1.17$ & 1.07 & $1.03-1.11$ \\
\hline $15-18$ & 1.10 & $1.04-1.15$ & 1.00 & $0.83-1.20$ \\
\hline Dispensed neuroleptika (N05) baseline year & 1.07 & $0.95-1.21$ & 1.03 & $0.87-1.21$ \\
\hline Dispensed analeptika (N06) baseline year & 1.05 & $0.92-1.21$ & 1.12 & $0.90-1.40$ \\
\hline Neighborhoodeducation quartile $1(<14 \%)^{3}$ & 1.01 & $0.99-1.03$ & 0.93 & $0.90-0.96$ \\
\hline Neighborhoodl education quartile $2(14-<20 \%)^{3}$ & 0.96 & $0.94-0.99$ & 0.92 & $(0.89-0.96)$ \\
\hline Neighborhood education quartile $3(20 \%<32 \%)^{3}$ & 1.04 & $1.01-1.07$ & 1.01 & $0.98-1.04$ \\
\hline Neighborhood education quartile $4(\geq 32 \%)^{3}$ & 1.05 & $1.03-1.06$ & 1.05 & $1.03-1.07$ \\
\hline Children $<2$ years of age & 1.06 & $1.04-1.07$ & 1.02 & $1.01-1.04$ \\
\hline Children $\geq 2$ years of age & 1.11 & $1.09-1.13$ & 1.06 & $1.04-1.09$ \\
\hline Stockholm & 1.04 & $1.02-1.06$ & 1.02 & $1.00-1.04$ \\
\hline Skåne & 1.09 & $1.07-1.12$ & 1.07 & $1.05-1.10$ \\
\hline Västra Götaland & 1.02 & $1.01-1.04$ & 0.99 & $0.98-1.01$ \\
\hline Västerbotten & 1.04 & $0.98-1.11$ & 1.02 & $0.95-1.10$ \\
\hline $\mathrm{NO}_{2}<15\left(\mu \mathrm{g} \cdot \mathrm{m}^{-3}\right)$ & 0.97 & $0.95-0.99$ & 0.93 & $0.91-0.95$ \\
\hline $\mathrm{NO}_{2} \geq 15\left(\mu \mathrm{g} \cdot \mathrm{m}^{-3}\right)$ & 1.11 & $1.09-1.14$ & 1.09 & $1.07-1.12$ \\
\hline
\end{tabular}

The estimates were not very precise (wide confidence intervals), but there was no clear evidence for medication of psychiatric disorders to influence the association between air pollution and asthma (Table 2). The association between air pollution and asthma medications seemed stronger in children 
with parents with high education than in children with parents with low education (Table 2). There was weak evidence for levels of socio-economy (education) in the neighborhood to have an impact on the association between $\mathrm{NO}_{2}$ and dispensed asthma medication, with an adjusted $\mathrm{OR}$ in areas with highest quartile of education level of 1.05 (95\% CI: 1.03-1.07). In the first three quartiles, there was no evidence for an association, with ORs close to 1 (Table 2). From Table 1, it is evident that the levels of air pollution were higher in area with the highest quartile of education level, so these results are consistent with the analysis showing an association mainly where $\mathrm{NO}_{2}$ concentrations are higher. The dispersion was also highest in quartile 4 , with a standard deviation of $11 \mu \mathrm{g} \cdot \mathrm{m}^{-3}$, in quartile $1-3,6.3,5.3$ and $5.1 \mu \mathrm{g} \cdot \mathrm{m}^{-3}$. The delay of start of follow-up and restricting the analysis to those who resided in the same address at least two years after follow-up did only marginally affect the estimates (data not shown). Adjusting for parental income only marginally affected the estimates (data not shown). There was some evidence of heterogeneity between counties ( $p$ for effect modification $=0.004$ ), but the results with mixed logistic regression with county as a level was similar to the ordinary logistic regression. The results with Cox regression was similar to the results generated with logistic regression (data not shown).

\section{Discussion}

In this large prospective cohort consisting of more than half of all Swedish children and adolescents, we observed evidence for air pollution to be associated with dispensed medications for asthma, especially in areas with comparatively higher levels of air pollution. We observed no clear evidence for our hypothesis, that stressors linked to low socio-economy or mental health problems would increase susceptibility to the effects of air pollution on the development of asthma On the contrary, the association between air pollution and asthma seemed stronger in children to parents with high education than with low education.

Our hypothesis derived from two earlier studies, where children exposed to a stressful environment at home seemed to have an increased susceptibility for air pollution-related asthma [16,17]. There are several potential explanations for the differences in findings that should be discussed. First of all, the two previous studies were an interview study of 73 children with asthma [16], and a prospective cohort study of 2497 children based on questionnaires [17], whereas we used data from national registers on a cohort of more than half of all Swedish children and adolescents. Using data from national registers has a major advantages in its longitudinal design and the high-quality data, for example selection bias is not a problem. However, the other two studies used more exact measures of stress, namely interviews of life stress [16] and parental stress from a perceived stress scale [17]. We used data on socio-economy and mental health, which although they are very crude indicators of stress, are relevant potential effect modifiers nevertheless. Furthermore, life-style factors may not have been fully accounted for in the analysis since we were restricted to variables that were present in the registers, which could have resulted in bias residual confounding. The potential confounders we had data on did not seem to have strong associations with neither outcome nor exposure however, although the effect estimates were somewhat attenuated when adjusting for them (Tables 1 and 2). The estimates were quite stable when adjusting for parental income and group-level socio-economy, which may indicate that residual confounding due to socio-economy is not likely. Secondly, another difference compared to the two previous studies was how we defined the outcome; namely as dispensing at least two asthma medications during follow-up, and we did not use information on diagnosis (doctor-diagnosed new onset asthma during 3 years of follow-up in one study [17] and biologic and clinical outcomes in children with asthma in the other study [16]). Medication use to describe health is increasingly used in the Nordic countries, where national registers provide the opportunity to do so [26,36,37]. Socioeconomic status could influence the probability to dispense medication, but that would also be true if using diagnosis as an outcome. It is well known that health care seeking behavior is highly dependent on socioeconomic status, also in Sweden which is one of the most equal countries in the world with a Gini coefficient of around 0.30 [38]. However, health care is free for every child younger 
than 18 years of age in Sweden, and medications are heavily subsidized example with respect to income differences. Our results may thus not be generalized to, or compare well with, countries with less access to welfare and health care. Thirdly, our study was conducted in Sweden, where air pollution are generally quite low (the two other studies were done in California [17] and Vancouver [16]), and we cannot rule out that mental health or socio-economic status would modify the association between air pollution and asthma in areas with higher levels of air pollution.

In the present study we used modeled levels of $\mathrm{NO}_{2}$, a marker of traffic-related air pollution, as exposure measure. Exposure misclassification must be considered in any study on long-term exposure to air pollution. We used exposure data from 2010 and assumed that differences (contrasts) in exposure would be similar back in time over the follow-up period (2005-2010), which is probably a reasonable assumption given the comparable short time period. An obvious source of exposure misclassification however is the fact that ambient exposure was modeled outdoors at the home address and that exposure at school, day-care or indoor exposure were not taken into account. We know from previous work that actual exposure may correlate only mildly with modelled outdoor exposure [39]. Furthermore, we used data on air pollution and start of follow-up as a marker for long-term exposure to air pollution. The validity of that assumption could of course be questioned, but we used a similar approach in the European Study of Cohorts for Air Pollution Effects (ESCAPE), and for that study we showed that when people changed residential address the air pollution concentrations were often similar at the new and old address. Exposure misclassification could theoretically bias the estimates both away and towards the null, if the misclassification is differential with respect to the outcome. Such misclassification is easy to imagine, for example if cohort members with respiratory symptoms and low socio-economy stay indoors more than cohort members with respiratory symptoms and high socio-economy, but it is difficult to speculate in size and direction of bias from such differential exposure misclassification. We have used the same approach as in many other air pollution epidemiology studies where we have been able to observe associations. For example, we observed strong associations between dispensed medications for psychiatric disorders and air pollution using almost exactly the same cohort and exposure measure as in the present study [26]. We believe, therefore, that exposure misclassification is an unlikely explanation for the results of the present study, at least if any true causal effect modification from any of the variables investigated on the association between traffic air pollution and asthma would be strong.

Furthermore, the associations cannot be explained by heterogeneity in prevalence or exposure across Sweden, as the pooled estimate (from county-specific estimates) seemed slightly higher than the non-pooled estimate. It is somewhat surprising that smoking during pregnancy did not seem to be clearly associated with asthma in the children in our study, since smoking during pregnancy seem to be a risk factor for asthma in children and adolescent [40,41], particularly for asthma or asthmatic symptoms during the first years of life [42-44]. An association between smoking during pregnancy and asthma in young children is supported in our data, where there was a univariate association between smoking during early pregnancy and the outcome, but only in children which were very young ( $<2$ years at study entry).

\section{Conclusions}

In conclusion, we observed associations between dispensed asthma medications and levels of air pollution at the home address, in areas where levels were comparatively high $\left(\mathrm{NO}_{2}\right.$ annual mean $\geq 15\left(\mu \mathrm{g} \cdot \mathrm{m}^{-3}\right)$. We observed evidence for the association to be stronger in children to parents with high education, but we did not observe support for our hypothesis that stressors linked to socio-economy or mental health problems would increase susceptibility to the effects of air pollution on the development of asthma.

Acknowledgments: The Umeå SIMSAM Laboratory data infrastructure used in this study was developed with support from the Swedish Research Council (2008-7491) and with strategic support from Umeå University. The work was funded by Vårdalstiftelsen with the Dnr VÅ 2011-25/430 (AO). 
Author Contributions: All authors contributed to the conception or design of the work, or the acquisition, analysis, or interpretation of data for the work, and drafted the work or revised it critically for important intellectual content and gave their final approval of the version to be published and agreed to be accountable for all aspects of the work in ensuring that questions related to the accuracy or integrity of any part of the work are appropriately investigated and resolved. Anna Oudin, Bertil Forsberg and Lennart Bråbäck conceived and designed the study. Anna Oudin acquired and analysed the data and drafted the manuscript. Daniel Oudin Åström helped interpret the data for the work and with the statistical analysis of the data.

Conflicts of Interest: The authors declare no conflict of interest.

\section{References}

1. Bråbäck, L.; Vogt, H.; Hjern, A. Migration and asthma medication in international adoptees and immigrant families in Sweden. Clin. Exp. Allergy 2011, 41, 1108-1115. [CrossRef] [PubMed]

2. Bråbäck, L.; Forsberg, B. Does traffic exhaust contribute to the development of asthma and allergic sensitization in children: Findings from recent cohort studies. Environ. Health 2009, 8, 17. [CrossRef] [PubMed]

3. Kozyrskyj, A.L.; Bahreinian, S.; Azad, M.B. Early life exposures: Impact on asthma and allergic disease. Curr. Opin. Allergy Clin. Immunol. 2011, 11, 400-406. [CrossRef] [PubMed]

4. Chen, E.; Fisher, E.B.; Bacharier, L.B.; Strunk, R.C. Socioeconomic Status, Stress, and Immune Markers in Adolescents with Asthma. Psychosom. Med. 2003, 65, 984-992. [CrossRef] [PubMed]

5. Chen, E.; Hanson, M.D.; Paterson, L.Q.; Griffin, M.J.; Walker, H.A.; Miller, G.E. Socioeconomic status and inflammatory processes in childhood asthma: The role of psychological stress. J. Allergy Clin. Immunol. 2006, 117, 1014-1020. [CrossRef] [PubMed]

6. Douwes, J.; Brooks, C.; Pearce, N. Stress and asthma: Hippocrates revisited. J. Epidemiol. Commun. Health 2010, 64, 561-562. [CrossRef] [PubMed]

7. Gregory, E.M.; Edith, C. Life Stress and Diminished Expression of Genes Encoding Glucocorticoid Receptor and $\beta_{2}$-Adrenergic Receptor in Children with Asthma. Proc. Natl. Acad. Sci. USA 2006, 103, 5496-5501.

8. Sandberg, S.; Paton, J.Y.; Ahola, S.; McCann, D.C.; McGuinness, D.; Hillary, C.R.; Oja, H. The role of acute and chronic stress in asthma attacks in children. Lancet 2000, 356, 982-987. [CrossRef]

9. Leander, M.; Lampa, E.; Rask-Andersen, A.; Franklin, K.; Gislason, T.; Oudin, A.; Svanes, C.; Torén, K.; Janson, C. Impact of anxiety and depression on respiratory symptoms. Respir. Med. 2014, 108, 1594-1600. [CrossRef] [PubMed]

10. Weil, C.M.; Wade, S.L.; Bauman, L.J.; Lynn, H.; Mitchell, H.; Lavigne, J. The relationship between psychosocial factors and asthma morbidity in inner-city children with asthma. Pediatrics 1999, 104, 1274-1281. [CrossRef] [PubMed]

11. Mogensen, N.; Larsson, H.; Lundholm, C.; Almqvist, C. Association between childhood asthma and ADHD symptoms in adolescence-A prospective population-based twin study. Eur. J. Allergy Clin. Immunol. 2011, 66, 1224-1230. [CrossRef] [PubMed]

12. Bowatte, G.; Lodge, C.; Lowe, A.; Erbas, B.; Perret, J.; Abramson, M.; Matheson, M.; Dharmage, S. The influence of childhood traffic-related air pollution exposure on asthma, allergy and sensitization: A systematic review and a meta-analysis of birth cohort studies. Allergy 2015, 70, 245-256. [CrossRef] [PubMed]

13. Gehring, U.; Gruzieva, O.; Agius, R.M.; Beelen, R.; Custovic, A.; Cyrys, J.; Eeftens, M.; Flexeder, C.; Fuertes, E.; Heinrich, J.; et al. Air pollution exposure and lung function in children: The ESCAPE project. Environ. Health Perspect. 2013, 121, 1357. [CrossRef] [PubMed]

14. Nordling, E.; Berglind, N.; Melén, E.; Emenius, G.; Hallberg, J.; Nyberg, F.; Pershagen, G.; Svartengren, M.; Wickman, M.; Bellander, T. Traffic-related air pollution and childhood respiratory symptoms, function and allergies. Epidemiology 2008, 19, 401-408. [CrossRef] [PubMed]

15. Mölter, A.; Simpson, A.; Berdel, D.; Brunekreef, B.; Custovic, A.; Cyrys, J.; de Jongste, J.; De Vocht, F.; Fuertes, E.; Gehring, U.; et al. A multicentre study of air pollution exposure and childhood asthma prevalence: The ESCAPE project. Eur. Respir. J. 2015, 45, 610-624.

16. Chen, E.; Schreier, H.; Strunk, R.; Brauer, M. Chronic traffic-related air pollution and stress interact to predict biologic and clinical outcomes in asthma. EHP 2008, 116, 970-975. [CrossRef] [PubMed] 
17. Shankardass, K.; McConnell, R.; Jerrett, M.; Milam, J.; Richardson, J.; Berhane, K. Parental stress increases the effect of traffic-related air pollution on childhood asthma incidence. Proc. Natl. Acad. Sci. USA 2009, 106, 12406-12411. [CrossRef] [PubMed]

18. Guxens, M.; Sunyer, J. A review of epidemiological studies on neuropsychological effects of air pollution. Swiss Med. Wkly. 2012, 141, w13322. [PubMed]

19. Sunyer, J.; Esnaola, M.; Alvarez-Pedrerol, M.; Forns, J.; Rivas, I.; López-Vicente, M.; Suades-González, E.; Foraster, M.; Garcia-Esteban, R.; Basagaña, X.; et al. Association between traffic-related air pollution in schools and cognitive development in primary school children: A prospective cohort study. PLoS Med. 2015, 12, e1001792. [CrossRef] [PubMed]

20. Chen, H.; Kwong, J.C.; Copes, R.; Tu, K.; Villeneuve, P.J.; van Donkelaar, A.; Hystad, P.; Martin, R.V.; Murray, B.J.; Jessiman, B.; et al. Living near major roads and the incidence of dementia, Parkinson's disease, and multiple sclerosis: A population-based cohort study. Lancet 2017, 389, 718-726. [CrossRef]

21. Oudin, A.; Forsberg, B.; Adolfsson, A.N.; Lind, N.; Modig, L.; Nordin, M.; Nordin, S.; Adolfsson, R.; Nilsson, L.-G. Traffic-related air pollution and dementia incidence in Northern Sweden: A longitudinal study. Environ. Health Perspect. 2016, 124, 306. [CrossRef] [PubMed]

22. Power, M.C.; Adar, S.D.; Yanosky, J.D.; Weuve, J. Exposure to air pollution as a potential contributor to cognitive function, cognitive decline, brain imaging, and dementia: A systematic review of epidemiologic research. Neurotoxicology 2016, 56, 235-253. [CrossRef] [PubMed]

23. Genc, S.; Zadeoglulari, Z.; Fuss, S.H.; Genc, K. The adverse effects of air pollution on the nervous system. J. Toxicol. 2012, 2012. [CrossRef] [PubMed]

24. Peen, J.; Schoevers, R.A.; Beekman, A.T.; Dekker, J. The current status of urban-rural differences in psychiatric disorders. Acta Psychiatr. Scand. 2010, 121, 84-93. [CrossRef] [PubMed]

25. Krabbendam, L.; van Os, J. Schizophrenia and Urbanicity: A Major Environmental Influence-Conditional on Genetic Risk. Schizophr. Bull. 2005, 31, 795-799. [CrossRef] [PubMed]

26. Oudin, A.; Bråbäck, L.; Åström, D.O.; Strömgren, M.; Forsberg, B. Association between neighbourhood air pollution concentrations and dispensed medication for psychiatric disorders in a large longitudinal cohort of Swedish children and adolescents. BMJ Open 2016, 6, e010004. [CrossRef] [PubMed]

27. Becerra, T.A.; Wilhelm, M.; Olsen, J.; Cockburn, M.; Ritz, B. Ambient air pollution and autism in Los Angeles county, California. Environ. Health Perspect. 2013, 121, 380-386. [CrossRef] [PubMed]

28. Volk, H.E.; Lurmann, F.; Penfold, B.; Hertz-Picciotto, I.; McConnell, R. Traffic-related air pollution, particulate matter, and autism. JAMA Psychiatry 2013, 70, 71-77. [CrossRef] [PubMed]

29. Newman, N.C.; Ryan, P.; LeMasters, G.; Levin, L.; Bernstein, D.; Hershey, G.K.K.; Lockey, J.E.; Villareal, M.; Reponen, T.; Grinshpun, S.; et al. Traffic-related air pollution exposure in the first year of life and behavioral scores at 7 years of age. Environ. Health Perspect. 2013, 121, 731. [CrossRef] [PubMed]

30. Forns, J.; Dadvand, P.; Foraster, M.; Alvarez-Pedrerol, M.; Rivas, I.; López-Vicente, M.; Suades-Gonzalez, E.; Garcia-Esteban, R.; Esnaola, M.; Cirach, M.; et al. Traffic-related air pollution, noise at school, and behavioral problems in Barcelona schoolchildren: A cross-sectional study. Environ. Health Perspect. 2016, 124, 529. [CrossRef] [PubMed]

31. McEwen, B.S.; Flier, J.S.; Underhill, L.H. Protective and Damaging Effects of Stress Mediators. N. Engl. J. Med. 1998, 338, 171-172. [CrossRef] [PubMed]

32. Lederbogen, F.; Kirsch, P.; Haddad, L.; Streit, F.; Tost, H.; Schuch, P.; Wust, S.; Pruessner, J.; Rietschel, M.; Deuschle, M.; et al. City living and urban upbringing affect neural social stress processing in humans. Nature 2011, 474, 498-501. [CrossRef] [PubMed]

33. Lindgren, U.; Nilsson, K.; de Luna, X.; Ivarsson, A. Data resource profile: Swedish microdata research from childhood into lifelong health and welfare (Umeå SIMSAM Lab). Int. J. Epidemiol. 2016, 45, 1075-1075g. [CrossRef] [PubMed]

34. Gustafsson, M.; Forsberg, B.; Orru, H.; Åström, S.; Tekie, H.; Sjöberg, K. Quantification of Population Exposure to $\mathrm{NO}_{2}, \mathrm{PM}_{2.5}$ and $P \mathrm{M}_{10}$ and Estimated Health Impacts in Sweden 2010; B 2197; IVL: Gothenburg, Sweden, 2014.

35. Sjöberg, K.; Haeger-Eugensson, M.; Forsberg, B.; Åström, S.; Hellsten, S.; Tang, L. Quantification of Population Exposure to Nitrogen Dioxide in Sweden 2005; Report B 1749; IVL: Falaise, France, 2007.

36. Damgaard, A.L.; Hansen, B.M.; Mathiasen, R.; Buchvald, F.; Lange, T.; Greisen, G. Prematurity and prescription asthma medication from childhood to young adulthood: A Danish national cohort study. PLoS ONE 2015, 10, e0117253. [CrossRef] [PubMed] 
37. Carlsen, H.K.; Zoëga, H.; Valdimarsdóttir, U.; Gíslason, T.; Hrafnkelsson, B. Hydrogen sulfide and particle matter levels associated with increased dispensing of anti-asthma drugs in Iceland's capital. Environ. Res. 2012, 113, 33-39. [CrossRef] [PubMed]

38. Popham, F.; Dibben, C.; Bambra, C. Are health inequalities really not the smallest in the Nordic welfare states? A comparison of mortality inequality in 37 countries. J. Epidemiol. Commun. Health 2013. [CrossRef] [PubMed]

39. Stroh, E.; Rittner, R.; Oudin, A.; Ardo, J.; Jakobsson, K.; Bjork, J.; Tinnerberg, H. Measured and modeled personal and environmental $\mathrm{NO}_{2}$ exposure. Popul. Health Metr. 2012, 10, 10. [CrossRef] [PubMed]

40. Harju, M.; Keski-Nisula, L.; Georgiadis, L.; Heinonen, S. Parental smoking and cessation during pregnancy and the risk of childhood asthma. BMC Public Health 2016, 16, 428. [CrossRef] [PubMed]

41. Hollams, E.M.; De Klerk, N.H.; Holt, P.G.; Sly, P.D. Persistent effects of maternal smoking during pregnancy on lung function and asthma in adolescents. Am. J. Respir. Crit. Care Med. 2014, 189, 401-407. [CrossRef] [PubMed]

42. Bråbäck, L.; Björ, O.; Nordahl, G. Early determinants of first hospital admissions for asthma and acute bronchitis among Swedish children. Acta Paediatr. 2003, 92, 27-33. [CrossRef] [PubMed]

43. Silvestri, M.; Franchi, S.; Pistorio, A.; Petecchia, L.; Rusconi, F. Smoke exposure, wheezing, and asthma development: A systematic review and meta-analysis in unselected birth cohorts. Pediatr. Pulmonol. 2015, 50, 353-362. [CrossRef] [PubMed]

44. Burke, H.; Leonardi-Bee, J.; Hashim, A.; Pine-Abata, H.; Chen, Y.; Cook, D.G.; Britton, J.R.; McKeever, T.M. Prenatal and passive smoke exposure and incidence of asthma and wheeze: Systematic review and meta-analysis. Pediatrics 2012, 129, 735-744. [CrossRef] [PubMed]

(C) 2017 by the authors. Licensee MDPI, Basel, Switzerland. This article is an open access article distributed under the terms and conditions of the Creative Commons Attribution (CC BY) license (http:// creativecommons.org/licenses/by/4.0/). 